\title{
Employers' search and the efficiency of matching
}

\author{
Michele Pellizzari* \\ London School of Economics \\ PRELIMINARY AND INCOMPLETE
}

May 11, 2004

\begin{abstract}
Labour turnover is typically higher in low productivity jobs. This paper suggests that this empirical finding is due to the matching process being less efficient at the bottom than at the top of the jobs' distribution. A simple theoretical model of employers' search shows that firms find it optimal to invest relatively little in advertisement and screening for low productivity jobs. This generates more separations and higher turnover. Original data from a sample of recruiting establishments in Britain, containing detailed information about employers' recruitment practices, are used to test the implications of the model.
\end{abstract}

Keywords: Labour turnover, Matching, Recruitment, Hiring.

\section{Introduction}

It is a relatively established empirical fact that labour turnover is usually higher in lower occupations and for unskilled workers compared to more productive jobs and more skilled workers (REFERENCES). For example, table 1 shows the fraction of workers who moved from employment into some other labour market status between two adjacent quarters in the United Kingdom for the

${ }^{*}$ I would like to thank Alan Manning, Steve Pischke and all participants to the CEP/LSE PhD Labour Market Workshops for useful comments and suggestions. Jon Hales kindly provided some additional data and clarified to me several data issues. Financial support from the ESRC, Bocconi University and University of Verona is gratefully acknowledged. All errors are my own responsibility. Contact address: m.pellizzari@lse.ac.uk 
years 2002 and 1995 by occupation in the starting job ${ }^{1}$. As it is evident from the figures in the first columns of each panel, labour turnover is always higher at the bottom than at the top of the jobs' distribution. About $8 \%$ to $10 \%$ of workers in elementary occupations change job or move into non-employment between two adjacent quarters, while this fraction is about $4 \%$ for managers.

Several explanations are possible for this empirical fact. A popular one suggests that people try to climb up the jobs ladder moving from lower level, lower paying jobs up to better ones (REFERENCES). Workers who already hold good jobs will tend to move less and this would then lead to the observed pattern of labour turnover. Alternatively, it has also been argued that young workers, who normally occupy jobs at a lower occupational level, change jobs frequently during their first years in the labour market in an attempt to explore their capabilities and to find job that meets their tastes (REFERENCES). However, these explanations don't seem to satisfactorily conform with some additional evidence. In fact, if workers at the bottom of the jobs' distribution would leave their jobs more often to look for better ones, as implied by both theories, we should observe more quits than layoffs at the bottom than at the top of the occupations' distribution. As the second columns of each panel in table 1 show, this is only partially true if one compares the very top occupation (managers and senior officials) with the very bottom (elementary occupations) but the numbers are much less clear for the other groups. In general, it is hard to argue that there clearly are more quits than layoffs at the bottom than at the top of the jobs' distribution.

Moreover, the same explanations would also suggest that more workers at the bottom would move to another, possibly higher, occupational group. Unfortunately, the data show (third column of each panel) that the fraction of workers who change job and move to a different occupation is rather constant across occupations, about $50 \%$.

This paper suggests a different explanation based on the idea that the matching process is less efficient for low productivity jobs, which will consequently be more prone to separation (both voluntary and involuntary). Employers find it optimal to invest relatively little in recruitment and screening activities for these types of jobs, while they are much more careful in the hiring of top level workers. Hence, matches of unskilled workers in low productivity jobs are more likely to be "bad", in the sense that the same worker (job) can be paired with another job (worker) into a more

\footnotetext{
${ }^{1} 2002$ is the most recent year for which this exercise is possible and 1995 is the closest one to the period which the data used in the rest of the paper refer to.
} 
productive match. This leads to more separations and more job instability for unskilled jobs in lower level occupations.

Data from an original sample of recruiting establishments in Britain will be used to support the argument outlined above. I will construct two measures of recruitment intensity: the number of recruitment methods activated for a single vacancy will be used as a measure of "extensive" recruitment (advertisement), the number of days between the first contact with the successful applicant and the first day of work will be used as a proxy for "intensive" recruitment (screening and interviewing). I will then show that employers invest more in both extensive and intensive recruitment for top level jobs and relatively little at the bottom of the jobs distribution. Finally, I will also document the correlation of the measures of extensive and intensive recruitment with various indicators of the quality of the match such as satisfaction of the employer with the recruit, initial wages and tenure.

LITERATURE REVIEW: 1. LABOUR TURNOVER 2. JOB INSTABILITY 3. EMPLOYER SEARCH

The paper is organised as follows: section 2 presents a simple model of optimal employer search, section 3 describes the data which will be used in section 4 to test empirically the implications of the model. Section 5 concludes.

\section{Employer's search: a theoretical framework}

The model in this section is both a simplification and an extension of the theory in Pellizzari (2004). The starting point is a simple matching model in which firms with unfilled vacancies and workers who need a job (or want to change job) look for each other. The existence of frictions in the labour market prevents them from meeting instantaneously and leads to positive rents associated with formed matches. For simplicity and clarity, the model is partial equilibrium and formalised in discrete time.

In each period a firm with an unfilled vacancy meets a jobseeker with probability $q(\theta)$, where $\theta$ represents labour market tightness, i.e. the ratio between vacancies and unemployment, $\theta=\frac{v}{u}$. According to the standard matching literature, $q(\theta)$ is assumed to be decreasing in $\theta$ : $\frac{\partial q(\theta)}{\partial \theta}<0$.

The first departure from the standard matching model consists in the introduction of hetero- 
geneity in the market, a crucial ingredient to make recruitment and screening activities play a meaningful role. For each vacancy there exists two types of workers, suitable and unsuitable. A suitable worker would produce a positive amount of output, $x=p$, once employed in the job, while an unsuitable worker would be totally unproductive ${ }^{2}$, i.e. $x=0$. The type of the match is unknown to both the worker and the firm until production takes place and output can be observed.

In order to focus on the choice of recruitment strategy by the employer, the supply side of the market - the search behaviour of workers - and the wage negotiation process are taken as exogenous and modelled as follows: firms offers wages equal to a fraction $\beta$ of expected productivity in the first period. If the worker then turns out to be suitable for the job, wages are updated to the same fraction $\beta$ of actual productivity $p$, otherwise the match is destroyed (by either of the two parties) and the vacancy re-opened. If the match is continued, a separation will only occur due to exogenous shocks with per-period probability $\lambda$.

There exist two types of recruitment activity. Extensive recruitment $(E)$ concerns all the actions taken by the employer to improve the probability of meeting a candidate or to increase the number of applications received. These activities include mostly advertisement but also asking employees, holding career events at colleges and professional schools, use of public or private employment agencies, etc. Formally, extensive recruitment requires a linear cost $c E$ and improves the probability of meeting a job candidate. Hence, we need to rewrite $q(\theta)$ as $q(E \mid \theta)$, where $E$ is a control variable for the firm and $\theta$ is an exogenous parameter. For an internal solution, we also need to assume $\frac{\partial q(E \mid \theta)}{\partial E}>0$ and $\frac{\partial q(E \mid \theta)}{\partial E \partial E}<0$. Finally, it seems reasonable to assume that the same level $E$ would have a stronger effect on $q(E \mid \theta)$ in a looser labour market: $\frac{\partial q(E \mid \theta)}{\partial E \partial \theta}<0$.

Intensive recruitment $(I)$ has to do with all the actions taken by the employer to improve her knowledge about the unobservable type of the worker. These actions include interviewing and screening candidates and take place once contact has been established and before deciding whether to hire or reject a candidate. Formally, intensive recruitment is modelled as follows: upon meeting a candidate the employer receives a signal about the type of the worker. The signal can take two values, "suitable" or "unsuitable", and it is correct with probability $\zeta(I)$. In other words, if the signal is "suitable" the candidate is suitable with probability $\zeta(I)$ and unsuitable with probability

\footnotetext{
${ }^{2}$ This extreme assumption is not crucial for the results of the model. Alternatively, one could make the assumption that unsuitable workers produce only a fraction $y \in[0,1]$ of $p$.
} 
$1-\zeta(I)$. Similarly if the signal is "unsuitable". The function $\zeta(I)$ needs to be increasing and concave in $I: \frac{\partial \zeta(I)}{\partial I}>0$ and $\frac{\partial \zeta(I)}{\partial I}<0$. Moreover, when $I=0$ the signal is totally uninformative and $\zeta(0)=1 / 2$. For simplicity, let us assume that the cost functions of $E$ and $I$ are identical - i.e. they are both linear with marginal cost $c$ - however the cost of $I$ is only paid if a candidate is actually met in a given period while $E$ has to be financed ex-ante.

Let us also assume that, for any given vacancy, there exists an exogenous fraction $\pi$ of suitable jobseekers in the economy. Finally, assume for the moment that the optimal hiring strategy for the firm is hiring when the signal is "suitable" and rejecting otherwise. Necessary and sufficient conditions for this to be optimal are derived in the appendix.

Given the above assumptions, the value of an unfilled vacancy for a representative firm can be written as follows:

$$
\begin{aligned}
V= & -c E+\frac{q(E \mid \theta)}{1+r}[-c I+\pi \zeta(I) J(p)+(1-\pi)(1-\zeta(I)) J(0)+(1-\pi) \zeta(I) V+\pi(1-\zeta(I)) V]+ \\
& +\frac{1-q(E \mid \theta)}{1+r} V
\end{aligned}
$$

where $J(p)$ and $J(0)$ are the value of a vacancy filled with a suitable (who produces $p$ ) and an unsuitable (who produces 0 ) candidate and can be written as:

$$
\begin{aligned}
& J(p)=p-w^{e}+\frac{1}{1+r} J \\
& J(0)=-w^{e}+\frac{1}{1+r} V
\end{aligned}
$$

where $w^{e}$ is the initial wage, paid as a fraction of expected productivity given that the signal is "suitable"

$$
w^{e}=\frac{\pi \zeta(I)}{\pi \zeta(I)+(1-\pi)(1-\zeta(I))} \beta p
$$

and $J$ is the continuation value of a job filled with a suitable candidate:

$$
\left(\frac{r+\lambda}{1+r}\right) J=(1-\beta) p+\lambda V
$$

\footnotetext{
${ }^{3}$ Only in this case the match would be actually formed.
} 
Substituting (5) and (4) into (2) and (3) and then everything into (1), one obtains:

$$
\begin{gathered}
V\left[r+q(E \mid \theta)-\frac{\pi \lambda}{\lambda+r} \frac{q(E \mid \theta)}{1+r} \zeta(I)-q(E \mid \theta)(1-\pi) \frac{1+r \zeta(I)}{1+r}-\pi q(E \mid \theta)(1-\zeta(I))\right]= \\
=-c(1+r) E-c q(E \mid \theta) I+\pi \frac{1+r+\lambda}{r+\lambda} q(E \mid \theta) \zeta(I)(1-\beta) p
\end{gathered}
$$

The optimal choice of $E$ and $I$ by the firm is described by the first order conditions of equation (6) with respect to these two control variables. The algebra is greatly simplified by imposing the usual equilibrium condition $V=0$.

$$
\begin{aligned}
\pi \frac{1+r+\lambda}{r+\lambda} q^{\prime}(E \mid \theta) \zeta(I)(1-\beta) p & =c\left[1+r+q^{\prime}(E \mid \theta) I\right] \\
\pi \frac{1+r+\lambda}{r+\lambda} \zeta^{\prime}(I)(1-\beta) p & =c
\end{aligned}
$$

Combining equation (7) and (8) yields:

$$
q^{\prime}(E \mid \theta) \frac{I}{1+r}=\frac{\eta_{\zeta}(I)}{1-\eta_{\zeta}(I)}
$$

where $\eta_{\zeta}(I)$ is the elasticity of the precision of the signal $\zeta(I): \eta_{\zeta}(I)=\frac{\partial \zeta(I)}{\partial I} \frac{I}{\zeta(I)}$.

Let us now describe intuitively the comparative statics effects of the parameters of the model. The appendix contains the formal derivation of these effects.

Equation (9) contains the first important result of the model. It shows that there is a positive correlation between $E$ and $I$. In other words, employers invest more in extensive recruitment when they also invest more in intensive screening. The intuition for this result is rather simple: as intensive recruitment increases the probability of eventually hiring a suitable candidate also increases, thus improving the marginal benefit of extensive recruitment.

From equation (9) it is also possible to derive the effect of labour market tightness, $\theta=\frac{v}{u}$, on $E$. Knowing that extensive recruitment and labour market tightness are substitutes, $\frac{\partial q(E \mid \theta)}{\partial E \partial \theta}<0$, it is straightforward to show that an increase in $\theta$ leads to a lower probability of meeting a candidate and induces lower effort in $E$. Note incidentally, that investment in intensive recruitment, being incurred on only if a candidate is actually met, is not influenced by labour market conditions ${ }^{4}$.

\footnotetext{
${ }^{4}$ This is evident from equation (8).
} 
Inspection of equation (8) allows to derive the effects of two other interesting parameters: productivity $(p)$ and the proportion of suitable workers $(\pi)$. They are both positively correlated with I. Intuitively, the effect of productivity is relatively simple: employers invest more in screening when recruiting for highly productive jobs. In this case, in fact, failing to hire the right worker is very costly: not only does it require paying a high wage without getting any output in return, but it also means re-opening the vacancy later on with high losses in terms of forgone output. As for the fraction of suitable workers, $\pi$, an increase in this parameter also increases the marginal benefit of intensive recruitment and therefore leads to more expenditure in screening activities. Note, however, that this argument holds only for values of $\pi$ that are consistent with the optimal hiring strategy assumed so far, i.e. hiring when the signal is good and rejecting otherwise. As it is discussed in more detail in the appendix, when $\pi$ is either too high or too low the optimal strategy changes and employers either hire anyone who makes contact with them, regardless of the signal received, or they do not open the vacancy in the first place.

So far we have discussed the implications of the model regarding the determinants of extensive and intensive recruitment and their correlation. Let us summarise the results as follows:

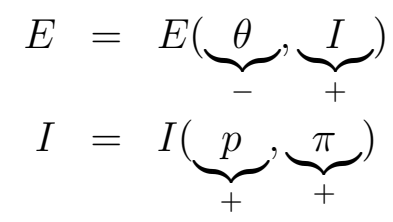

Furthermore, the model allows to draw empirically testable implications on various measures of match quality as well. For example, equation (4) shows that more intensive recruitment $(I)$ and a higher fraction of suitable workers $(\pi)$ both have a positive impact on initial wages, $w^{e}$. More interesting for the initial motivation of this paper is the effect on the separation rate. The model contains two separation processes, one endogenous and one exogenous. The latter one (exogenous) hits "good" matches (i.e. jobs filled with suitable workers) with exogenous probability $\lambda$ every period and it is unaffected by the endogenous variables of the model. The endogenous separation process refers to "bad" matches (jobs filled with unsuitable candidates) being immediately destroyed as soon as production is observed. The probability that a newly created match is endogenously destroyed corresponds to the probability of its being a "bad" match: 


$$
\operatorname{Pr}\{\text { endogenous separation }\}=\frac{(1-\pi)(1-\zeta(I))}{\pi \zeta(I)+(1-\pi)(1-\zeta(I))}
$$

Empirically, this suggests that the probability of a separation occurring close to the engagement decreases with intensive screening.

Extensive recruitment, on the other hand, has a direct effect on $q(E \mid \theta)$, the probability of meeting a candidate and therefore on vacancy duration.

To summarise, the model delivers three sets of empirical implications. First, it predicts that extensive and intensive recruitment are positively correlated. Second, it allows to identify the determinants of recruitment effort (implications (10) and (11)). Third, it indicates that recruitment effort, in the form of both extensive and intensive recruitment, is correlated with various outcome measures. In particular, extensive recruitment $(E)$ positively affects the meeting probability $(q(E \mid \theta))$ and, consequently, vacancy duration. Intensive recruitment $(I)$ directly affects initial wages and the overall quality of the match, reducing the probability of separation (equation (12)).

In the remaining of the paper, after describing the data in the next section, I will test empirically the implications of the model.

\section{The data: the 1992 Survey of Employers' Recruitment Practices (SERP)}

The data used for the empirical implementation of the model come from an original survey conducted in the United Kingdom in 1992, the Survey of Employers' Recruitment Practices (SERP). This study

was carried out by the British Social and Community Planning Research (SCPR) on behalf of the Employment Service. It was mainly aimed at investigating the use of public employment services by private employers as compared to the use of alternative recruitment methods.

To this end, one would ideally like to have information about a representative sample of engagements occurred in a determined time window. However, since the total population of all engagements is not easily recorded anywhere, it is rather difficult to extract such a sample. The approach taken by researchers at SCPR is based on a sample of 10,000 establishments, drawn from the 1989 Census of Employment where an establishment is defined as "the activities of a single employer at a single 
set of premises". The Census covered all exiting establishments with 25 or more employees and a random sample of smaller establishments.

The subsample of 10,000 establishment extracted from the Census was designed to contain enough observations to conduct statistical analysis by regions and establishment size. A purely random sample would have led to too many establishments located in London and the South East and too few establishments of small size (below 20-25 employees). For this reason, small firms and firms outside London and the South East were oversampled. Moreover, since the purpose of the study was the analysis of recruitment practices, which are usually similar across establishments belonging to the same organisation, another sampling adjustment was made in order to limit the number of units belonging to the same large firm (e.g. large food stores, etc.).

The 10,000 establishments were first contacted in Autumn 1991 via a brief preliminary telephone interview to collect the information necessary to categorize them along two dimensions: in-scope versus out-of-scope establishments and recruiting versus non-recruiting establishments. Out-ofscope establishments were firms that had closed down or moved between the census in 1989 and the date of the telephone interview. They were excluded from the study. Recruiting establishments were defined as establishments that either had recruited one or more employees in the previous 12 months or had unfilled vacancies at the time of the interview. A recruit or engagement was defined as "recruiting an employee, where a new contract of employment is involved".

All in-scope recruiting establishments were then contacted for a longer face-to-face interview, which forms the main source of information for the final survey. For budgetary reasons, only about half of the non-recruiting firms were contacted for a second short telephone interview. Eventually, the final survey contains information about 5,635 recruiting and 614 non-recruitment establishments. The final interviews took place between May and November 1992 and the respondent was meant to be the main person responsible for the recruitment process. They were either personnel specialists (16\%), general managers $(27 \%)$, branch-depot managers $(20 \%)$ or professional staff $(9 \%)$.

Only the sample of recruiting establishments is needed for the purpose of this paper. Few observations have been dropped due to missing or incorrect values, leading to 5,343 valid establishments, which, corrected for the weights provided by the SCPR to recover the representativeness for the entire population of recruiting establishments, represent 6083 firms. The questions regarding the establishments were grouped into 3 sections of the questionnaire. The first one contains general en- 
quires about the type of firm and activity as well as questions about the role of the respondent. The second section asks about the characteristics of the workforce, including information about current vacancies and recruits that were taken on in the previous 12 months. The third section includes detailed questions about the recruitment practices usually adopted by the firm. The descriptive statistics for the sample of establishments are reported in table 2.

A sample of recruits was then constructed from the 5,635 recruiting establishments according to the following rules. The total number of engagements that took place in the 12 months prior to the interview was recorded and divided into the 9 major groups of the Standard Occupational Classification (SOC). If there had been engagements in more than 5 occupational groups, the most recent one in each of the 5 groups in which the largest number of engagements had been made were selected. Otherwise, if recruitment only occurred in fewer than 5 occupational groups but in total more then 5 new recruits were taken on, the most recent in each group was selected, then, starting with the most numerous group, the second most recent engagements was selected, continuing in this way until 5 engagements were selected. Finally, if fewer than 5 engagements were made in the previous 12 months, all of them were selected regardless of the occupational group. This led to a sample of 22,707 engagements.

A set of detailed questions for each of the selected engagements were asked, including the characteristics of the job that was offered, those of the successful applicant, accurate information about the duration of the vacancy, the recruitment methods activated and their sequence, whether the recruit was still employed at the firm and how satisfied the employer was with him/her. However, not all questions were asked for all engagements. The most completed set of information was collected for the first engagements, i.e. the most recent.

For this paper some observations had to be dropped from the original sample due to missing or incorrect values, resulting in a valid sample of 17,193 engagements, which, rescaled using the weights provided by SCPR to recover the representativeness of all engagements that took place in the selected establishments, represent 13,367 new employment contracts. The descriptive statistics for the sample of engagements used in this paper are reported in table 3. 


\section{Testing the empirical implications of the model}

Before moving on to the empirical test of the model, it is worth checking the level of labour turnover by occupation in our sample. Respondents to the SERP report the composition of employment at their establishment by occupation, also indicating the fraction of employees in each group that have been employed at the firm for more than 12 months. The responses are coded in intervals and are shown in table 4 . The last line of the table gives an overall estimate of the fraction of employees in each group that have worked at the firm for at least 12 months by taking the mid point in each interval. These numbers are also plotted in figure 1.

Results from table 4 and figure 1 broadly confirm the discussion over table 1: there seems to be a general trend towards more stable employment relationships in higher occupations. Apart from the peaks for managers, craft/skilled service workers and operatives/assembly workers, higher occupations typically display a higher incidence of long-lasting employment contracts.

Once confirmed that data from the SERP support the basic empirical fact that motivates this paper, we can move on to the test of the various empirical implications of the theory presented in section 2. For clarity, let's classify these implications in three groups. First, the relationship between extensive and intensive recruitment: the model predicts that investment in these two types of recruitment activities are positively correlated (equation (9)). The second set of implications describes the determinants of recruitment effort, both intensive and extensive (equations (8) and $(9))$ : employers invest more in intensive screening $(I)$ when recruiting for highly productive jobs

(i.e. higher occupations). Finally, the third set of implications addresses the initial question of the paper and relates the quality of the match to the effort exerted in recruiting: the probability of a separation soon after hiring is lower when intensive screening is stronger (12) and vacancy duration is shorter when extensive recruitment is stronger. Given the difficulty in observing $\pi$, the composition of workers' types in the economy, this parameter is assumed to be constant within regions. Regional dummies will be introduced in the estimation to control for different levels of $\pi$ as well as of other region specific factors.

Before testing these implications, it is crucial to choose two empirically measurable indicators of extensive $(E)$ and intensive $(I)$ recruitment. In the remaining of the paper, extensive recruitment will be measured as the number of recruitment channels activated for a vacancy, while intensive 
recruitment as the number of days between contact with the successful applicant is first made and his/her first day of work. However, this second measure could be affected by a number of other factors like the need for the selected applicant to give notice to a previous employer or to finish an educational course. In order to avoid these problems, when the length of the screening process is used as a measure of intensive recruitment the sample is restricted to vacancies that are immediately available to be filled (e.g. there was no previous person still employed in that position) and that were taken by candidates who were not either employed or in full-time education in another job at the time of the first contact. The distributions of these two measures are shown in figures 2 and 3 .

Test 1: the correlation between extensive and intensive recruitment The empirical counterpart of equation (9) is a regression of extensive recruitment on intensive screening, controlling for labour market tightness. Alternatively, looking at the same relationship in the opposite direction, the same results should be obtained from a regression of intensive on extensive recruitment, again controlling for labour market tightness. Results from both these approaches are shown in table 5 . Since information about the length of the screening process is only available for the most recent engagement, only one recruit per establishment is available for this estimation.

The first column of table 5 reports results from an ordered probit regression with the number of recruitment methods on the left hand side and screening intensity and labour market tightness as exogenous regressors. Labour market tightness is measured, here as well as in all the other regressions reported below, as the ratio between the number of unfilled vacancies and the number of unemployment benefit claimants in the region where the establishment is located and in the quarter during which the engagement took place ${ }^{5}$. The estimates confirm the prediction of the model from equation (9): employers use more methods to advertise a vacancy when they also take more time to screen applicants. As labour market tightness increases, the model predicts that recruitment effort declines. The point estimate for $\theta=\frac{v}{u}$ in the first column of table 5 has the expected negative sign but it is not significant.

In the second column the same relationship between $E$ and $I$ is investigated in the opposite direction. Now the number of days between the first meeting with the successful applicant and

\footnotetext{
${ }^{5}$ Due to the presence of regional dummies in all the equations, the effect of $\theta$ is eventually identified by the time-variation across quarters.
} 
his/her first day of work is moved on the left had side of the equation and is regressed on a set of dummies for the number of recruitment methods activated and $\theta$. The estimation method also

needs to be changed to a standard Poisson regression that takes into account the discrete nature of the dependent variable. Results are consistent with what has been previously found in column 1: the screening process is longer when more recruitment methods are activated (although this effect starts to revert for vacancies with 6 or more recruitment channels used). The effect of $\theta$ is now negative and significant.

Test 2: the determinants of extensive and intensive recruitment Equations (8) and (9) imply that both intensive and extensive recruitment are positively correlated with productivity $(p)$. Extensive recruitment is also negatively affected by labour market tightness $(\theta)$. This is tested in table 6 where our measures of recruitment effort are regressed on regional labour market tightness and a set of indicators of the productivity of the match, such as the occupational group, the type of contract and whether the job requires supervising other workers.

The estimation method is different in column 1, where the dependent variable is the number of recruitment methods activated for the vacancy, and in column 2, where the length of the screening process is on the left hand side. In the first case, the equation is estimated using an ordered probit regression to take into account the ordered nature of the dependent variable. In column 2 a Tobit regression is used to account for the lower limit at zero days of the the dependent variable. A set of additional controls is also introduced in the regressions including all available establishment characteristics as well as the personal characteristics of the successful applicant and regional dummies.

For the estimation of the equation in column 1, more than one recruit per establishment is available and the standard errors of the regression are adjusted accordingly, to allow for correlation between observations related to the same firms. In column 2, this is not a problem because information about the length of the screening process is only available for the most recent engagement.

Results strongly confirm the implication that recruitment effort is stronger, both in terms of extensive and intensive activities, when employer are filling high-productivity jobs. In both column 1 and 2, vacancy that offer non-permanent contracts are significantly associated with lower recruitment effort. Also, the estimated coefficients for the set of occupational dummies clearly indicate 
that, when recruiting for high level jobs employers, activate several recruitment channels and screen longer.

The effect of labour market tightness is more controversial. The coefficients on $\theta$ in column 1 contradicts the implication of the model by indicating that the number of recruitment methods activated for the same vacancy increases in tight labour markets. The same coefficient in column 2 is not significant, as predicted by equation (8). It also interesting to note the effect of the establishment's size: larger firms tend to exert more recruitment effort.

Test 3: recruitment effort and the quality of matches The final set of empirical implications relates recruitment effort to various outcomes. Let us start with the effects of extensive recruitment. In the model $E$ is assumed to be positively correlated with the meeting probability, $q(E \mid \theta)$. Empirically this implies that when more recruitment channels are activated for the same vacancy more applications are received and vacancy duration is shorter. These are the correlations tested in table 7.

The correlation between extensive recruitment and the number of applications received ${ }^{6}$ for a vacancy is investigated in the first two columns. The coefficients reported here are obtained from a Poisson regression with the number of received applications on the left hand side and our measure of extensive recruitment on the right hand side, together with a large of set of controls. The equation is estimated using a Poisson regression to account for the discrete nature of the dependent variable. It is also important to notice that information about applications is only available for the most recent engagement and only for those cases when contact with the successful applicant is made through a formal method (i.e. newspaper advertisement, internal and/or external notices, agencies). This reduces the sample to 1863 unweighted engagements.

In column 1 extensive recruitment is introduced linearly while in column two a separate dummy is used for each cumulative number of activated methods. In both cases the results are uncontroversial: activating more recruitment channels leads to more applications being received for the same vacancy.

The last two columns of table 7 explore the correlation of extensive recruitment and vacancy

\footnotetext{
${ }^{6}$ The number of applications per vacancy in this dataset is much higher than similar statistics from other studies (REFERENCES). This is probably due to the overrepresentation of large establishments in the SERP which often have multiple vacancy openings.
} 
duration, measured as the number of weeks between the beginning of the recruitment process and the first meeting with the successful applicant. However, this information is recorded using different time units: if the total duration is shorter than 4 weeks, it is recorded in days otherwise in weeks. This peculiar aspect of the data requires some adjustment to the econometric model.

\section{TO BE COMPLETED...}

The estimates from this adjusted duration model are reported in the last two columns of table 7. The results are in contrast with the predictions of the model: apparently when more recruitment methods are activated the hazard of vacancy filling is lower, thus leading to longer vacancy duration. It is also interesting to notice that these results indicate a negative and significant duration dependence. This is consistent with some (REFERENCES), but not all (REFERENCES) studies in this area.

Let us now move on to the empirical analysis of the effects of intensive recruitment. The results, reported in table 8, are more supporting. This table reports estimates of the correlation between our measure of intensive screening and three measures of match quality: satisfaction with the recruit, tenure and initial wages. In the first case a probit regression has been estimated for the probability of being very satisfied with the person recruited on the length of the recruitment process and a set of controls, including all observable establishment's and individual's characteristics. In several cases $(12 \%)$ the respondent could not answer the question because the recruit had been at the firm for a too short period. These observations have been dropped from the sample. The results strongly support the prediction that a longer, and presumably more accurate, screening period is associated with more satisfaction about the person taken on.

The second column of table 8 reports the estimates from a duration model for tenure. About $7 \%$ of the recruits had already left the firm at the time of the interview. Using these completed employment spells, as well as the uncompleted tenure durations of those still employed, it is possible to identify the effect of screening intensity on the probability that the match is destroyed soon after hiring. However, here too it is necessary to make some adjustments to the standard econometric method. Uncompleted durations can be computed in days using information about the date of the interview and the date when the recruit started his/her job. Uncompleted durations, however, are recorded in intervals: when the person has already left the firm the responded is only asked to indicate whether he/she had been employed less than a week, between a week and a month, etc. 


\section{TO BE COMPLETED...}

Results are reported in the second column of table 8 and clearly show that a longer screening process reduced the hazard of the match being destroyed, as implied by equation (12).

Finally, the third column of table 8 shows the coefficients obtained from a standard OLS regression of the log of the initial wage (gross and hourly) on a set of controls and our measure of recruitment intensity. The estimates confirm the predictions of equation (4) from the model: initial wages are significantly higher when the screening process is longer.

\section{Conclusions}

TO BE ADDED... 


\section{References}

[1] Abowd J.M., Kramarz F. (2003), "The costs of hiring and separation", Labour Economics, 10, 499-530.

[2] Albrecht J., van Ours J.C. (2001), "Using employer hiring behaviour to test the educational signalling hypothesis, CEPR Discussion Paper 2968.

[3] Barron M.,J., Black D.A., Loewenstein M.A. (1987), "Employer size: the implications for search, training, capital investment and wage growth", Journal of Labor Economics, 5(1), 76-89.

[4] Behrenz L. (2001), "Who gets the job and why? An explorative study of employers' recruitment behavior", Journal of Applied Economics, 4(2), 255-278.

[5] Behrenz L. (2002), "The employment service and vacancy duration", Evaluation Review, 26(6), 602-617.

[6] Bentolila S., Bertola G. (1990), "Firing costs and labour demand: how bad is Eurosclerosis", Review of Economic Studies, 57(3), 381-402.

[7] Berman E. (1997), "Help wanted, job needed: estimates of a matching function from employment service data", Journal of Labor Economics, 15(1), S251-S292.

[8] Blanchard O.J., Diamond P., Hall R.E., Yellen J. (1989), "The Beveridge curve", Brookings Papers on Economic Activity, 1989(1), 1-76.

[9] Bollinger C.R., Hotchkiss J.L. (2003), "The upside potential of hiring risky workers: evidence from the baseball industry", Journal of Labor Economics, 21(4), 923-944.

[10] Booth A., Chen Y., Zoega G. (2002), "Hiring and Firing: a tale of two thresholds", Journal of Labor Economics, 20(2), 217-248.

[11] Brown D., Dickens R., Gregg P., Machin S., Manning A. (1999), "Everything under a fiver: recruitment and retention in lower paying labor markets", Joseph Rowntree Foundation. 
[12] Burdett K., Cunningham E.J. (1998), "Toward a theory of vacancies", Journal of Labor Economics, 16(3), 445-478.

[13] Chan W. (1996), "External recruitment versus internal promotion", Journal of Labor Economics, 14(4), 555-570.

[14] Coles M.G., Smith E. (1998), "Marketplaces and Matching", International Economic Review, 39(1), 239-254.

[15] Dohmen T.J., Pfann G.A. (2004), "Workers separations in a nonstationary corporate environment", European Economic Review, 48, 645-663.

[16] Falk A., Lalive R., Zweimuller J. (2004), "The success of job applications: a new approach to program evaluation", IZA Discussion Paper, 1100.

[17] Farber H.S. (1994), "The analysis of interfirm worker mobility", Journal of Labor Economics, 12(4), 554-593.

[18] Givord P., Maurin E. (2004), "Changes in job security and their causes: an empirical analysis for France, 1982-2002", European Economic Review, 48, 595-615.

[19] Gorter C., van Ommeren J. (1999), "Sequencing, timing and filling rates of recruitment channels", Applied Economics, 31, 1149-1160.

[20] Gorter C., Hassink W.H.J., Russo G. (2003), "The structure of hiring and labour market tightness", Economics Letters, 80, 99-103.

[21] Hamermesh D.S., Pfann G.A. (1996), "Adjustment costs in factor demand", Journal of Economic Literature, 34(3), 1264-1292.

[22] Holzer H.J., Katz L.F., Krueger A.B. (1991), "Job queues and wages", Quarterly Journal of Economics, 106(3), 739-768.

[23] Holzer H.J. (1994), "Job vacancy rates in the firm: an empirical analysis", Economics, 61(241), 17-36. 
[24] Jovanovic B. (1979a), "Job matching and the theory of turnover", Journal of Political Economy, 87(1), 972-990.

[25] Jovanovic B. (1979b), "Firm-specific capital and turnover", Journal of Political Economy, 87(6), 1246-1260.

[26] Kletzer L.G. (1998), "Journal of Economic Perspectives, 12(1), 115-136.

[27] Manning A. (2000), "Pretty vacant: recruitment in low-wage labour markets", Oxford Bulletin of Economics and Statistics, 62, 747-770.

[28] Manning A. (2003), "Monopsony in motion", Princeton University Press.

[29] Mortensen D.T. (1978), "Specific capital and labor turnover", Bell Journal of Economics, 9(2), 572-586.

[30] van Ours J., Ridder G. (1991), "Cyclical variation in vacancy durations and vacancy flows", European Economic Review, 35, 1143-1155.

[31] van Ours J., Ridder G. (1992), "Vacancies and the recruitment of new employees", Journal of Labor Economics, 10(2), 138-155.

[32] Pellizzari M. (2004), "Do friends and relatives really help in getting a good job?", CEP Discussion Paper 623.

[33] Pissarides C.A. (1979), "Job matchings with State Employment Agencies and random matching", The Economic Journal, 89(356), 818-833.

[34] Rosén A. (2003), "Search, bargaining and employer discrimination", Journal of Labor Economics, 21(4), 807-829.

[35] Russo G., Gorter C., Nijkamp P., Rietveld P. (1997), "Employers' recruitment behaviour: an empirical analysis of the role of personnel management attitudes", Labour, 11(3), 599-623.

[36] Shimer R. (2003), "The assignment of workers to jobs in an economy with coordination frictions", Department of Economics, University of Chicago. 
[37] Topel R.H., Ward M.P. (1992), "Job mobility and the careers of young men", Quarterly Journal of Economics, 107(2), 439-479. 
6 Appendix

TO BE ADDED... 


\section{Figures and Tables}


Figure 1: Estimated turnover

(source: Survey of Employers Recruitment Practices, 1992)

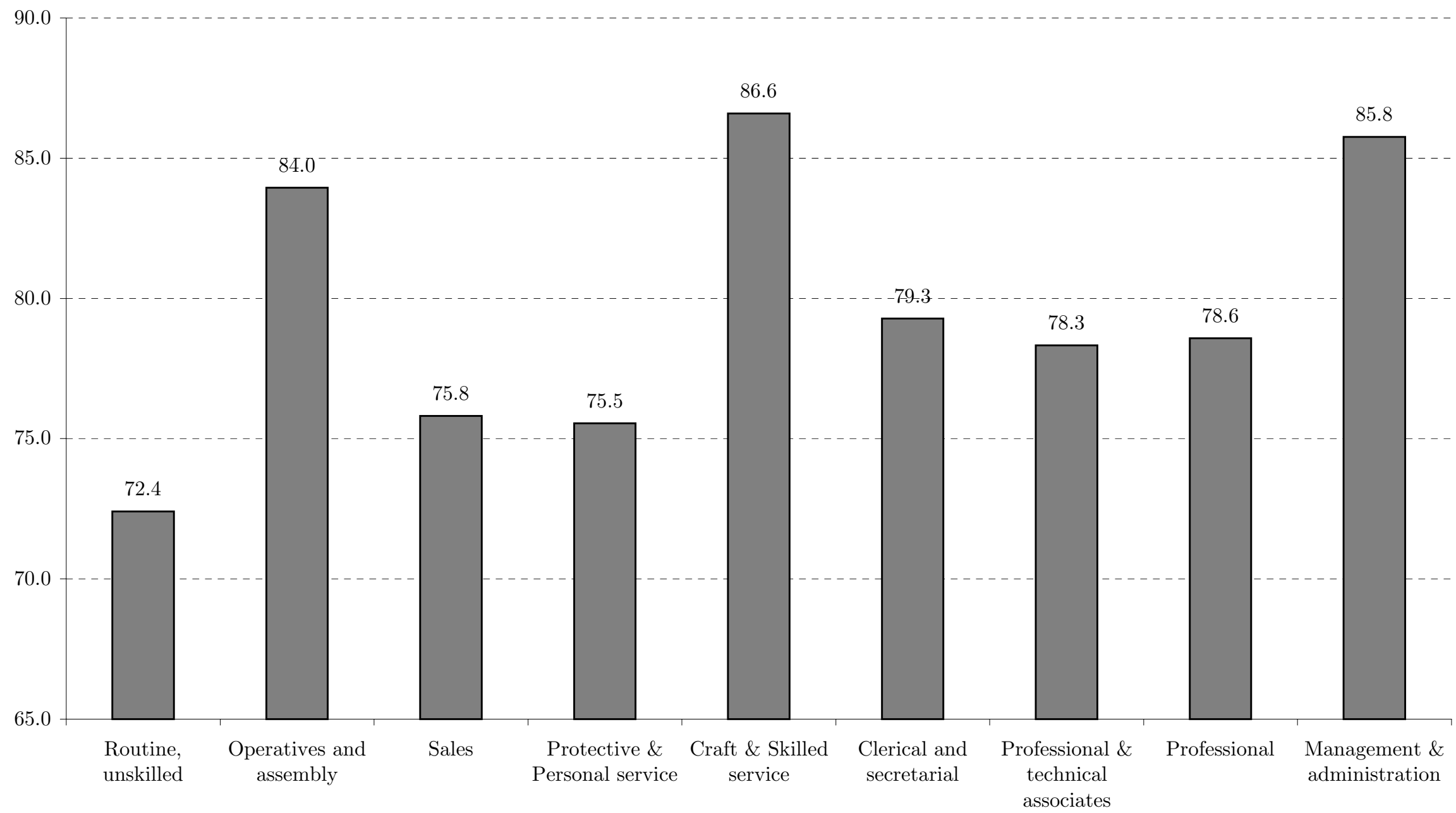


Figure 2: Extensive recruitment: number of recrutiment methods used for the same vacancy

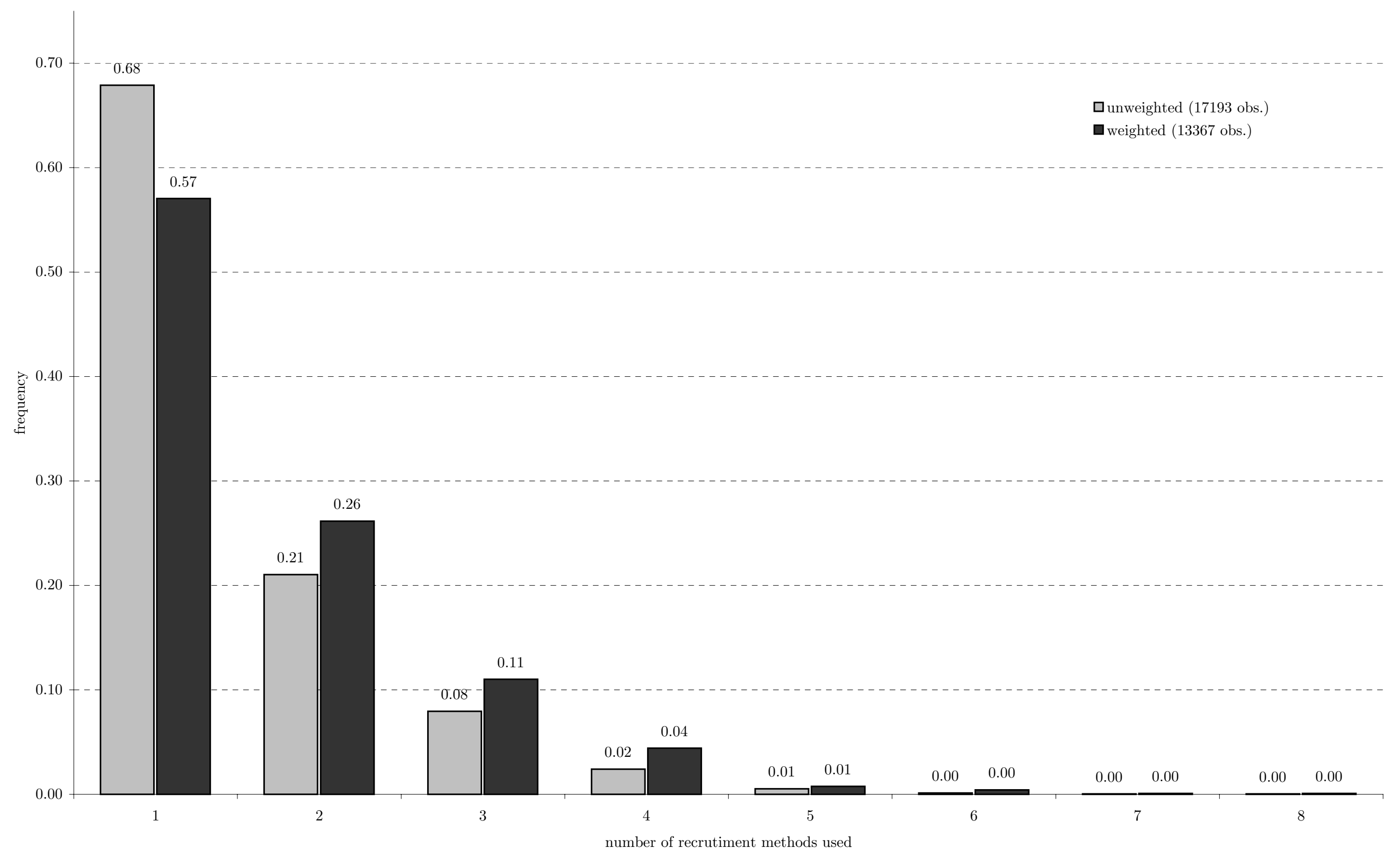


Figure 3: Intensive recruitment: lenght of the screening process

(\# of days between the first contact is made with the successful applicant and his/her first day of work)

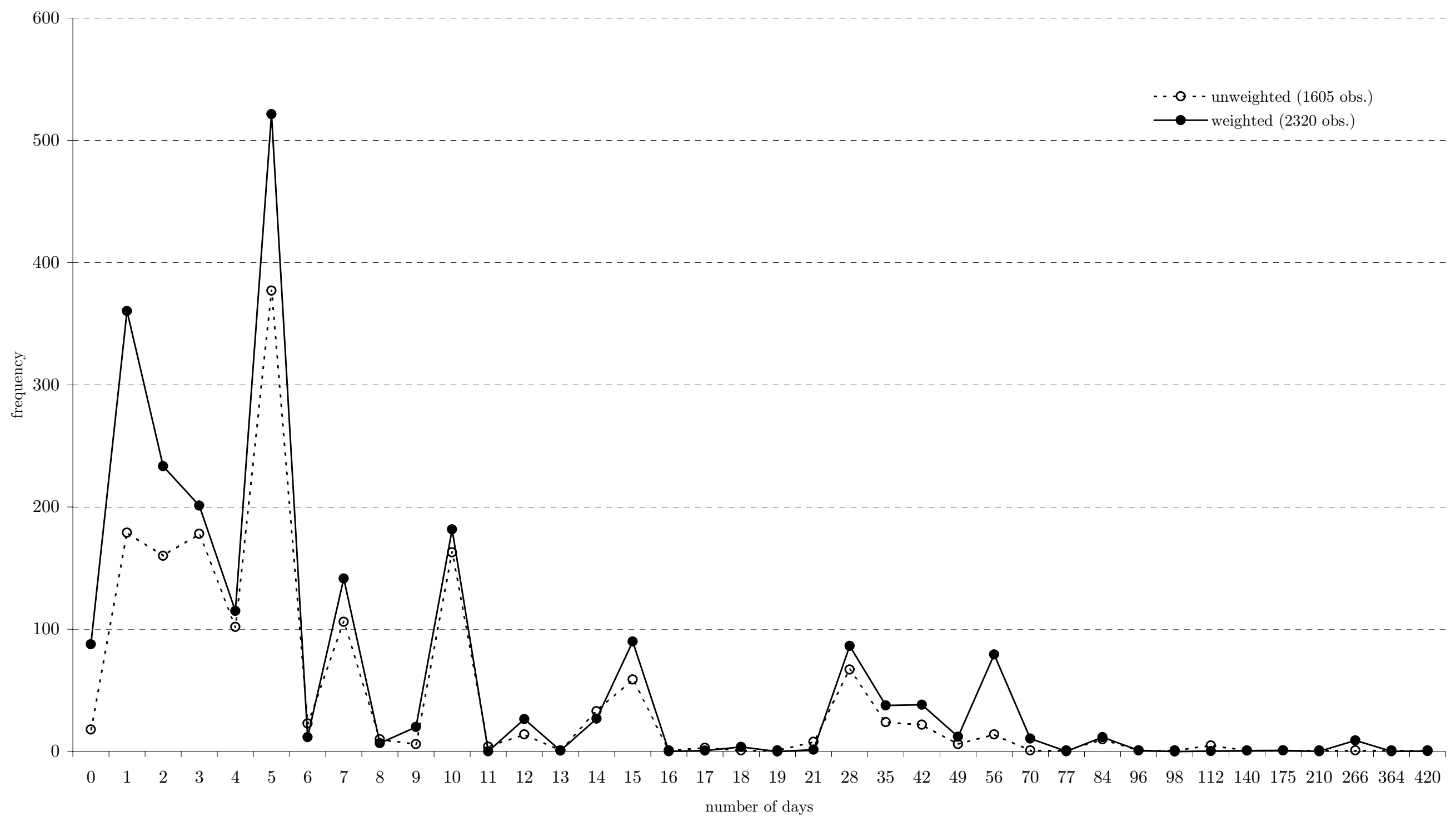

The sample is restricted to new or unfilled vacancies (i.e. vacancies where the previous person is still employed are excluded) and to workers who, at the time of recruitment were either unemployed or inactive (i.e. job-to-job and education-to-job movers are excluded) 
Table 1: Labour turnover, layoffs and industry switches by occupation

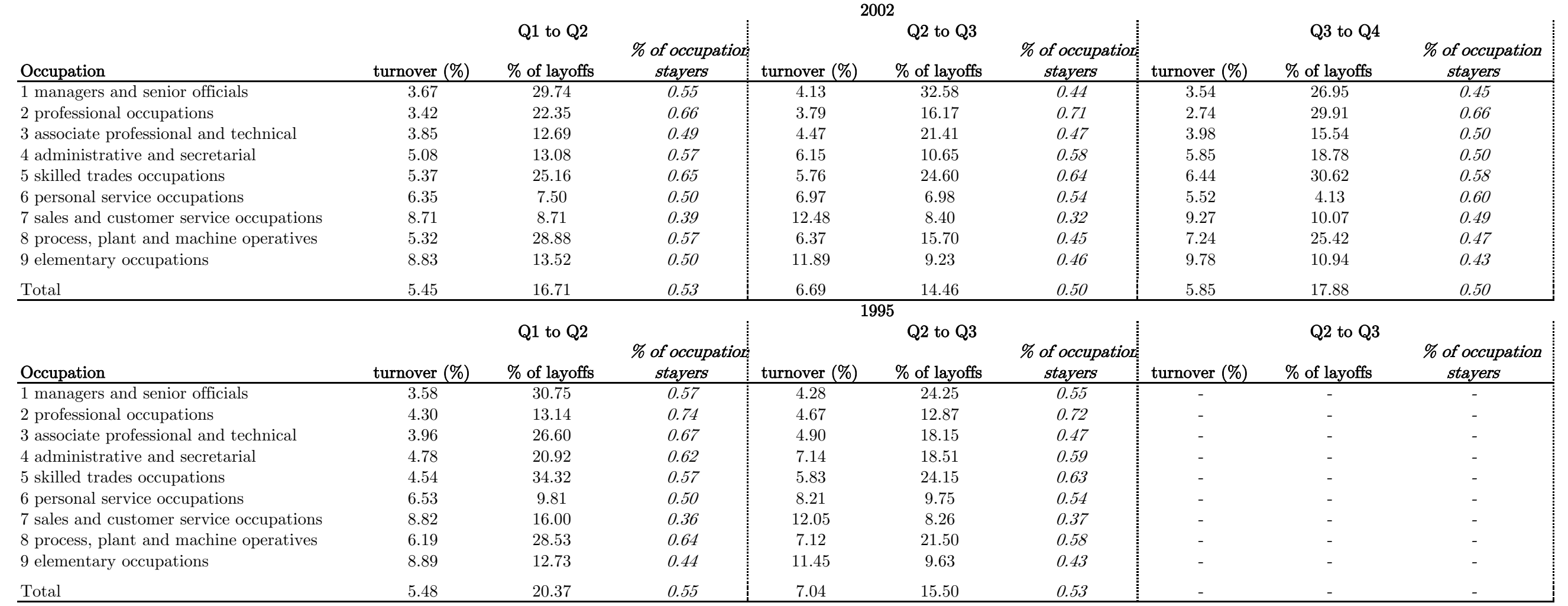

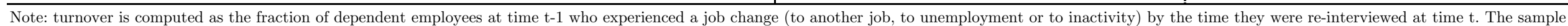
excludes transitions to retirement.

The $\%$ of industry stayers is computed as the fraction of dependent employees at time $\mathrm{t}-1$ who are observed in another job but in the same industry at time $\mathrm{t}$ over the total number of job-to-job switchers

Source: Quarterly Labour Force Survey 
Table2: Descriptive statistics for the sample of establishments

\begin{tabular}{|c|c|c|}
\hline \multirow[b]{2}{*}{ Sample size } & unweighted & weighted \\
\hline & 5343 & 6083 \\
\hline Variable & Mean & Mean \\
\hline employment & $314.829(778.555)$ & $40.530(0.959)$ \\
\hline manual workers ${ }^{1}$ & $0.304(0.302)$ & $0.214(0.007)$ \\
\hline professionals $^{2}$ & $0.260(0.238)$ & $0.285(0.006)$ \\
\hline \multicolumn{3}{|l|}{ Labour intensity (labour costs as \% of total costs) } \\
\hline less than $25 \%$ & $0.217(0.412)$ & $0.233(0.010)$ \\
\hline $25 \%$ to $50 \%$ & $0.292(0.455)$ & $0.306(0.012)$ \\
\hline $50 \%$ to $75 \%$ & $0.187(0.390)$ & $0.167(0.009)$ \\
\hline more than $75 \%$ & $0.304(0.460)$ & $0.293(0.012)$ \\
\hline \multicolumn{3}{|l|}{ Industry } \\
\hline energy, water, etc. & $0.013(0.111)$ & $0.004(0.001)$ \\
\hline metal, minerals, etc. & $0.044(0.205)$ & $0.017(0.003)$ \\
\hline metal goods, engineering, etc. & $0.112(0.316)$ & $0.059(0.006)$ \\
\hline other manufacturing & $0.127(0.333)$ & $0.059(0.005)$ \\
\hline construction & $0.033(0.179)$ & $0.031(0.004)$ \\
\hline distribution, catering, etc. & $0.221(0.415)$ & $0.326(0.012)$ \\
\hline transport and communication & $0.039(0.195)$ & $0.047(0.006)$ \\
\hline Banking, insurance, etc. & $0.150(0.357)$ & $0.172(0.010)$ \\
\hline other services & $0.261(0.439)$ & $0.284(0.011)$ \\
\hline \multicolumn{3}{|l|}{ Trend in activity in the past 12 months } \\
\hline expanding & $0.405(0.491)$ & $0.433(0.012)$ \\
\hline contracting & $0.199(0.399)$ & $0.157(0.009)$ \\
\hline \multicolumn{3}{|l|}{ Capital utilisation } \\
\hline below full capacity & $0.468(0.499)$ & $0.485(0.013)$ \\
\hline overloaded & $0.013(0.112)$ & $0.016(0.003)$ \\
\hline $1=$ change of ownership in the past 3 years & $0.127(0.333)$ & $0.104(0.008)$ \\
\hline \multicolumn{3}{|l|}{ Region } \\
\hline London & $0.068(0.252)$ & $0.114(0.009)$ \\
\hline rest of South East & $0.103(0.305)$ & $0.195(0.012)$ \\
\hline East Anglia & $0.038(0.192)$ & $0.039(0.005)$ \\
\hline South West & $0.103(0.304)$ & $0.094(0.007)$ \\
\hline West Midlands & $0.105(0.307)$ & $0.091(0.007)$ \\
\hline East Midlands & $0.074(0.262)$ & $0.071(0.006)$ \\
\hline York/Humbershire & $0.101(0.301)$ & $0.088(0.006)$ \\
\hline North West & $0.115(0.319)$ & $0.124(0.008)$ \\
\hline North & $0.095(0.294)$ & $0.042(0.004)$ \\
\hline Wales & $0.094(0.292)$ & $0.051(0.004)$ \\
\hline Scotland & $0.102(0.303)$ & $0.091(0.007)$ \\
\hline \multicolumn{3}{|l|}{ Establishments by number of engagements } \\
\hline One & $0.147(0.354)$ & $0.293(0.013)$ \\
\hline Two & $0.132(0.339)$ & $0.197(0.011)$ \\
\hline Three & $0.144(0.351)$ & $0.142(0.009)$ \\
\hline Four & $0.201(0.401)$ & $0.157(0.009)$ \\
\hline Five & $0.376(0.485)$ & $0.212(0.009)$ \\
\hline
\end{tabular}

Standard erros in paretheses

1. routine, unskilled, operatives and assembly workers

2. professional and technical associates, professionals, managers and administrators

Source: Survey of Employers Recruitment Practices, 1992 
Table 3: Descriptive statistics for the sample of recruits

\begin{tabular}{cccc}
\multicolumn{3}{c}{ unweighted } & \multicolumn{2}{c}{ weighted } \\
Mean & $(\mathrm{sd}) \quad$ valid obs. & Mean $(\mathrm{sd})$ & valid obs. \\
\hline
\end{tabular}

The vacancy

supervisory job

non permanent contract ${ }^{3}$

Hourly pay (gross)

Occupation

Routine, unskilled
Operatives and assembly
Sales
Protective/Personal service
Craft/Skilled service
Clerical and secretarial
Professional and technical associates
Professional
Management/administration

$\begin{array}{ll}0.17(0.38) & 17193 \\ 0.22(0.41) & 17193 \\ 5.22(3.45) & 17193\end{array}$

$0.14(0.01) \quad 13367$

$0.37(0.02) \quad 13367$

$5.46(0.10) \quad 13367$

$\begin{array}{llll}0.15(0.36) & 17193 & 0.14(0.01) & 13367\end{array}$

$\begin{array}{llll}0.15(0.35) & 17193 & 0.23(0.01) & 13367\end{array}$

$\begin{array}{llll}0.12(0.32) & 17193 & 0.07(0.01) & 13367\end{array}$

$\begin{array}{llll}0.07(0.26) & 17193 & 0.07(0.01) & 13367\end{array}$

$\begin{array}{llll}0.09(0.29) & 17193 & 0.07(0.01) & 13367\end{array}$

$\begin{array}{llll}0.19(0.39) & 17193 & 0.20(0.01) & 13367\end{array}$

$\begin{array}{llll}0.08(0.28) & 17193 & 0.09(0.01) & 13367\end{array}$

$\begin{array}{llll}0.08(0.27) & 17193 & 0.09(0.01) & 13367\end{array}$

$\begin{array}{llll}0.07(0.26) & 17193 & 0.04(0.00) & 13367\end{array}$

The succesful applicant

female

Age

\begin{tabular}{|c|c|c|c|c|}
\hline & & & & \\
\hline $16-18$ & $0.08(0.28)$ & 17193 & $0.07(0.01)$ & 13367 \\
\hline $19-24$ & $0.26(0.44)$ & 17193 & $0.29(0.01)$ & 13367 \\
\hline $25-34$ & $0.33(0.47)$ & 17193 & $0.37(0.02)$ & 13367 \\
\hline $35-44$ & $0.20(0.40)$ & 17193 & $0.19(0.01)$ & 13367 \\
\hline $45-54$ & $0.10(0.30)$ & 17193 & $0.07(0.01)$ & 13367 \\
\hline 55 or over & $0.03(0.16)$ & 17193 & $0.01(0.00)$ & 13367 \\
\hline \multicolumn{5}{|l|}{ Ethinc group } \\
\hline White & $0.95(0.21)$ & 17193 & $0.92(0.01)$ & 13367 \\
\hline Black, etc & $0.02(0.13)$ & 17193 & $0.03(0.00)$ & 13367 \\
\hline Asian & $0.02(0.15)$ & 17193 & $0.04(0.01)$ & 13367 \\
\hline Other & $0.01(0.08)$ & 17193 & $0.01(0.00)$ & 13367 \\
\hline disable & $0.02(0.13)$ & 17193 & $0.02(0.00)$ & 13367 \\
\hline \multicolumn{5}{|l|}{ Outcome variables } \\
\hline \multicolumn{5}{|l|}{ Satisfaction } \\
\hline not at all satisfied & $0.01(0.11)$ & 17193 & $0.00(0.00)$ & 13367 \\
\hline not very satisfied & $0.02(0.15)$ & 17193 & $0.01(0.00)$ & 13367 \\
\hline fairly satisfied & $0.26(0.44)$ & 17193 & $0.25(0.01)$ & 13367 \\
\hline very satisfied & $0.61(0.49)$ & 17193 & $0.47(0.02)$ & 13367 \\
\hline too ealy to say & $0.09(0.29)$ & 17193 & $0.26(0.02)$ & 13367 \\
\hline number of applications received ${ }^{2}$ & $43.71(98.44)$ & 1863 & $59.17(9.78)$ & 2345 \\
\hline vacancy duration (days) ${ }^{3}$ & $35.58(50.39)$ & 4221 & $46.07(2.88)$ & 5772 \\
\hline until meeting with successful applicant & $16.79(27.69)$ & 4226 & $22.28(1.42)$ & 5798 \\
\hline from meeting to first day of work & $19.05(34.11)$ & 4309 & $23.83(1.87)$ & 5985 \\
\hline \multicolumn{5}{|l|}{ The labour market } \\
\hline unemployment rate ${ }^{4}$ & $8.92(1.16)$ & 17193 & $8.85(0.04)$ & 13367 \\
\hline Labour market tightness ${ }^{5}$ & $4.65(1.67)$ & 17193 & $4.51(0.05)$ & 13367 \\
\hline
\end{tabular}

1. Temporary, casual, part-time contracts

2. This question is only asked for the most recent engagement and only when contact with the successful applicant was made through a formal recruitment method (i.e. newspaper advertisment, notices, agencies)

3. Number of days between starting to use the sucessful recruitment method and the first day of work of the succesful candidate. These questions are only asked for the most recent engagement.

4. The unemployment rate is measured as the regional average during the quarter in which the recruit started working. (Source: Nomis)

5. Ratio between unfilled vacancies and unemployment benefit claimants in the quarter in which the recruit started working. (Source: Nomis)

Source: Survey of Employers Recruitment Practices, 1992. 
Table 4: Turnover by Occupational Groups

$\%$ of existing employees who have been working for the same organisation continuously over the past 12 months

\begin{tabular}{|c|c|c|c|c|c|c|c|c|c|}
\hline & $\begin{array}{l}\text { Routine, } \\
\text { unskilled }\end{array}$ & $\begin{array}{c}\text { Operatives and } \\
\text { assembly }\end{array}$ & Sales & $\begin{array}{c}\text { Protective \& } \\
\text { Personal service } \\
\end{array}$ & $\begin{array}{c}\text { Craft \& Skilled } \\
\text { service }\end{array}$ & $\begin{array}{c}\text { Clerical and } \\
\text { secretarial }\end{array}$ & $\begin{array}{c}\text { Professional \& } \\
\text { technical associates }\end{array}$ & Professional & $\begin{array}{r}\text { Management \& } \\
\text { administration } \\
\end{array}$ \\
\hline $0 \%$ & 0.59 & 0.57 & 1.34 & 1.48 & 0.95 & 0.49 & 0.82 & 0.83 & 1.49 \\
\hline $1 \%-9 \%$ & 1.34 & 0.93 & 0.71 & 1.14 & 1.38 & 0.90 & 1.31 & 0.71 & 0.86 \\
\hline $10 \%-19 \%$ & 0.32 & 0.51 & 0.79 & 0.60 & 0.29 & 0.86 & 2.13 & 1.51 & 0.57 \\
\hline $20 \%-39 \%$ & 3.68 & 1.12 & 5.92 & 1.77 & 0.84 & 1.16 & 1.14 & 2.16 & 1.02 \\
\hline $40 \%-59 \%$ & 14.45 & 5.02 & 8.93 & 3.31 & 1.83 & 2.55 & 4.09 & 2.62 & 0.71 \\
\hline $60 \%-79 \%$ & 16.57 & 10.04 & 15.68 & 23.52 & 5.33 & 12.52 & 14.65 & 18.33 & 4.10 \\
\hline $80 \%-89 \%$ & 17.24 & 16.91 & 22.45 & 28.68 & 11.44 & 24.68 & 23.19 & 20.06 & 10.42 \\
\hline $90 \%$ or over & 40.20 & 62.99 & 42.04 & 34.51 & 75.83 & 50.56 & 48.33 & 49.30 & 77.26 \\
\hline not stated & 5.61 & 1.92 & 2.14 & 5.00 & 2.12 & 6.28 & 4.34 & 4.48 & 3.57 \\
\hline Total & 100.00 & 100.00 & 100.00 & 100.00 & 100.00 & 100.00 & 100.00 & 100.00 & 100.00 \\
\hline Estimated turnover & 72.40 & 83.95 & 75.81 & 75.54 & 86.59 & 79.28 & 78.33 & 78.58 & 85.75 \\
\hline
\end{tabular}

Source: Survey of Employers Recrutiment Practices, 1992 


\section{Table 5: Correlation between intensive and extensive recruitment ${ }^{1}$}

Dependent variable Estimation method
\# recruitment methods used ordered probit

[1] lenght of recruitment (days) ${ }^{2}$ poisson regression

length of recruitment (days) ${ }^{2} \quad 0.005^{* *}$

\# of recruitment methods used

2 methods used
3 methods used
4 methods used
5 methods used
6 methods used
7 methods used
8 methods used

Labour market tightness $(\mathrm{v} / \mathrm{u})^{3}$

Constant

Observations

1. The sample is restricted to new or unfilled vacancies (i.e. vacancies where the previous person is still employed are excluded) and to workers who, at the time of recruitment were either unemployed or inactive (i.e. job-to-job and education-to-job movers are excluded)

2. \# of days between the first contact is made with the successful applicant and his/her first day of work

3. Ratio between unfilled vacancies and unemployment benefit claimants in the quarter in which the recruit started working. (Source: Nomis)

Robust standard errors (clustered by region) in parentheses

* significant at $10 \% ; * *$ significant at $5 \%$; *** significant at $1 \%$ 
Table 6: The determinants of recruitment intensity

Extensive recruitment

Dependent variable

Estimation method
\# recruitment methods used ordered probit
Intensive recruitment ${ }^{1}$

length of recruitment (days) ${ }^{2}$

Tobit regression

Regional labour market

tightness $(\mathrm{v} / \mathrm{u})^{4}$

$0.066^{*}$

$(0.034)$

$-0.052$

Type of job

supervisory

0.022

0.361

$(0.032)$

(2.108)

$-0.188^{* * *}$

$-3.821^{* * *}$

non-permanent

(0.033)

Occupational category

operatives \& assembly

$0.174^{* * *}$

(0.049)

$0.284^{* * *}$

sales

(0.049)

$4.459 * *$

$0.242^{* * *}$

(2.091)

protective/personal services

(0.051)

$5.282^{* *}$

$0.247^{* * *}$

(2.308)

craft/skilled service

1.927

$0.311^{* * *}$

(2.154)

clerical \& secretarial

(0.039)

prof. ass. \& techinical

$0.302^{* * *}$

(0.047)

$0.280^{* * *}$

(0.051)

$0.256^{* * *}$

$7.512^{* * *}$

(2.134)

$12.089^{* * *}$

(3.387)

$14.108^{* * *}$

(0.054)

Establishment's size

$$
\begin{gathered}
\text { \# of employees } \\
\text { \# of employees }{ }^{\wedge} 2
\end{gathered}
$$$$
0.034^{* * *}
$$$$
-0.001^{* * *}
$$

Establishment's characteristics ${ }^{5}$

Recruit's characteristics ${ }^{6}$

yes

yes

yes

yes

17193

1605

$-15125.24$

Observations

$-7045.12$

1. The sample is restricted to new or unfilled vacancies (i.e. vacancies where the previous person is still employed are excluded) and to workers who, at the time of recruitment were either unemployed or inactive (i.e. job-to-job and educationto-job movers are excluded)

2. \# of days between the first contact is made with the successful applicant and his/her first day of work

3. This dummy is equal to 1 if the recruit received some formal training (i.e. off-the-job training at the establishment or at another location, or formal on-the-job training).

4. Ratio between unfilled vacancies and unemployment benefit claimants in the quarter in which the recruit started working. (Source: Nomis)

5. Occupational composition of the workforce, labour intensity (\% of labour costs over total costs), capital utilization (below full capacity, overloaded), activity trend (expanding vs. contracting), a dummy for change of ownership in the past 3 years, dummies for company type (limited, partnership, charity, et.), dummies for establishment type (administrative vs.

production, headquarter vs. non-headquarter), industry dummies, regional dummies.

6. Gender dummy, age dummies, ethnic group dummies, disable dummy.

Robust standard errors (clustered by establishment in column 1 and by region in column 2) in parentheses

* significant at $10 \%$; $*$ significant at $5 \%$; ** significant at $1 \%$ 
Table 7: The effects of extensive recruitment

Dependent variable

Mean of dep. Variable

Estimation method
\# of applications received ${ }^{1}$ 59.16 poisson regression

\# of recruitment methods used

$$
\text { [1] }
$$

$0.232^{* * *}$

$(0.045)$

2 methods used

3 methods used

4 methods used

5 methods used

6 methods used

7 methods used

8 methods used

Regional labour market

tightness $(\mathrm{v} / \mathrm{u})^{3}$

$0.230^{*}$

(0.130)

Type of job
$-0.332^{*}$
$(0.182)$
-0.053

$(0.135)$

non-permanent

Establishment's size

$$
\begin{array}{r}
\text { \# of employees } \\
\text { \# of employees } ` 2
\end{array}
$$

Occupational dummies

Establishment's characteristics ${ }^{4}$

Duration dependence:

$$
\begin{array}{r}
\text { (log) elapsed duration } \\
1=1 \text { week } \\
1=2 \text { weeks } \\
1=3 \text { weeks } \\
1=4 \text { weeks }
\end{array}
$$

Observations Individuals

Log Likelihood

1863

1863
$0.244^{*}$

$0.165^{* *}$
$(0.071)$

$0.302^{* * *}$

$(0.103)$

$1.088 * * *$

(0.157)

$-0.017$

$(0.418)$

0.761

(0.776)

-

$$
\begin{gathered}
-0.365^{* *} \\
(0.175) \\
-0.043 \\
(0.129)
\end{gathered}
$$

$$
\begin{gathered}
0.106^{* * *} \\
(0.023) \\
-0.003^{* * *} \\
(0.001)
\end{gathered}
$$

yes yes

$$
\begin{gathered}
0.112^{* * *} \\
(0.025) \\
-0.003^{* * *} \\
(0.001)
\end{gathered}
$$

yes yes
$-0.026$

(0.052)

$0.076^{*}$

(0.039)

$-0.030 * * *$
$(0.004)$
$0.000 * * *$

(0.000)

yes

yes

$-0.574^{* * *}$
$(0.073)$
$-0.910^{* * *}$
$(0.166)$
$-0.405^{* * *}$
$(0.096)$
$0.149^{*}$
$(0.083)$
$0.883^{* * *}$

(0.079)

1863

$-71753.62$
1863

$-70771.05$
13817

4241

$-7842.55$
$-0.132^{* * *}$

(0.048)

$-0.238^{* * *}$

(0.059)

$-0.246^{* *}$

(0.101)

$-0.045$

(0.124)

$-0.254^{*}$

(0.140)

$-1.079 * * *$

(0.110)

$-1.428^{* * *}$

(0.083)

$-0.014$

(0.046)

$-0.025$

(0.052)

$0.076^{*}$

(0.040)

$-0.030 * * *$

(0.004)

$0.000^{* * *}$

(0.000)

yes

yes

$0.576^{* * *}$

(0.073)

$-0.916^{* * *}$

(0.166)

$-0.409 * * *$

(0.095)

$0.147^{*}$

(0.082)

$0.882^{* * *}$

13817

4241

$-7839.08$

1. The sample is restricted to vacancies filled through a "formal" recruitment method (i.e. the successful applicant is first contacted through newspaper advertisement, internal or external notices, recruitment agencies, both public and private).

2. \# of weeks between the beginning of the search process and the first contact with the successful applicant.

3. Ratio between unfilled vacancies and unemployment benefit claimants in the quarter in which the recruit started working.

(Source: Nomis)

4. Establishment size and composition, labour intensity (\% of labour costs over total costs), capital utilization (below full capacity, overloaded), activity trend (expanding vs. contracting), a dummy for change of ownership in the past 3 years, dummies for company type (limited, partnership, charity, et.), dummies for establishment type (administrative vs. production, headquarter vs. non-headquarter), industry dummies, regional dummies.

Robust standard errors (clustered by regions) in parentheses

* significant at $10 \% ; * *$ significant at $5 \% ; * * *$ significant at $1 \%$ 


\section{Table 8: Intensive recruitment and the quality of the match ${ }^{1}$}

Dependent variable

Mean of dep. Variable

Estimation method
$1=$ very satisfied with the recruit
0.60
probit

length of recruitment (days) ${ }^{3}$

[1]

$0.018^{* *}$

(0.007)

0.523

(0.422)

0.163

non-permanent

$-0.232$

(0.196)

$(\mathrm{v} / \mathrm{u})^{4}$

Establishment's size

$$
\begin{gathered}
\text { \# of employees } \\
\text { \# of employees ^2 }
\end{gathered}
$$

Occupational dummies

Establishment's characteristics ${ }^{5}$

Recruit's characteristics ${ }^{6}$

Duration dependence:

$$
\begin{array}{r}
(\mathrm{log}) \text { elapsed tenure } \\
1=4 \text { weeks } \\
1=12 \text { weeks } \\
1=24 \text { weeks }
\end{array}
$$

Observations

Log Likelihood

$\begin{array}{cc}\text { Tenure (weeks) } & (\log ) \text { initial wage }{ }^{2} \\ 18.7 & 1.4 \\ \text { proportional hazard } & \text { OLS }\end{array}$ $[2]$

$-0.031^{* *}$

(0.014) [3]

$0.001^{* *}$

(0.000)

$0.158^{* * *}$

$-0.017$

$-0.182$

$0.012^{* * *}$

$(0.004)$

$-0.002$

$-0.000^{*}$

\section{yes}

yes

yes

$$
\begin{aligned}
& \text { yes } \\
& \text { yes } \\
& \text { yes }
\end{aligned}
$$

yes
yes
yes

-
-
-
-
$-19.918^{* * *}$
$30.333^{* * *}$
$54.475 * * *$
(1.584)
$69.873^{* * *}$

1381

1381

$-605.19$

1605

1605

1. The sample is restricted to new or unfilled vacancies (i.e. vacancies where the previous person is still employed are excluded) and to workers who, at the time of recruitment were either unemployed or inactive (i.e. job-to-job and education-to-job movers are excluded) 2. Gross and hourly.

3. \# of days between the first contact is made with the successful applicant and his/her first day of work

4. Ratio between unfilled vacancies and unemployment benefit claimants in the quarter in which the recruit started working. (Source: Nomis)

5. Occupational composition of the workforce, labour intensity (\% of labour costs over total costs), capital utilization (below full capacity, overloaded), activity trend (expanding vs. contracting), a dummy for change of ownership in the past 3 years, dummies for company type (limited, partnership, charity, et.), dummies for establishment type (administrative vs. production, headquarter vs. nonheadquarter), industry dummies, regional dummies.

6. Gender dummy, age dummies, ethnic group dummies, disable dummy.

Robust standard errors (clustered by regions) in parentheses

* significant at $10 \%$; * significant at $5 \% ; * * *$ significant at $1 \%$ 